\title{
PENGARUH EFIKASI DIRI TERHADAP PRESTASI BELAJAR SISWA DI SMA NEGERI SE-KECAMATAN NAMLEA
}

\author{
Syafa Lisaholit ${ }^{1}$ Siti Hajar Loilatu ${ }^{2}$ M Chairul Basrun Umanailo ${ }^{3}$ \\ ${ }^{1,2}$ Fakultas Ilmu Keguruan dan Ilmu Pendidikan, Universitas Iqra Buru \\ ${ }^{3}$ Fakultas Pertanian dan Kehutanan, Universitas Iqra Buru \\ 1,2,3 Jl. Prof Bassalamah No 1, Namlea, 97571 \\ ${ }^{1}$ Email: syafalisaholit28@gmail.com \\ 2Email: stloilatu@gmail.com \\ ${ }^{3}$ Email: chairulbasrun@gmail.com
}

\begin{abstract}
ABSTRAK
Pengaruh Efikasi Diri,Aktifitas Belajar dan Kemandirian Belajar Terhadap Prestasi Belajar Biologi Pada Siswa Kelas X SMA Negeri Se-Kecamatan Namlea.Rumusan masalah dalam penelitian ini adalah bagaimana pengaruh efikasi diri terhadap prestasi belajar siswa di SMA sekecamatan Namlea.Penelitian ini bertujuan untuk mengetahui pengaruh efikasi diri terhadap prestasi belajar biologi siswa kelas $\mathrm{X}$ negeri sekecamatan namlea. Jenis penelitian adalah ex-post facto yang bersifat kausalitas yang dirancang untuk menerangkan adanya hubungan sebab akibat antar variabel. Populasi dalam penelitian ini berjumlah 603 siswa SMA Negeri sekecamatan namlea. Sampel dalm penelitian ini berjumlah 90 siswa. Teknik analisis data menggunakan analisis regresi linear sederhana. Hasil analisis menunjukan bahwa efikasi diri berpengaruh positif dan signifikan terhadap prestasi belajar Biologi siswa Kelas X SMA Negeri se-kecamatan namlea. Dilihat dari hasil perhitungan regresi linear sederhana dapat diketahui besarnya pengaruh yaitu 0.271.Besarnya nilai R squarenya 0,036 . Sehingga dapat diketahui besarnya sumbangan relatif pengaruh efikasi diri terhadap prestasi belajar sebesar 36,0\% sedangkan $64 \%$ dipengaruhi oleh variabel lain yang tidak diteliti dalam penelitian.
\end{abstract}

Kata Kunci: Efikasi Diri, Belajar, Prestasi

\begin{abstract}
The Effect of Self-Efficacy, Learning Activities and Learning Independence on Biology Learning Achievement in Class X Students of Public Senior High Schools in Namlea District.The formulation of the problem in this study is how the effect of self-efficacy on student achievement in high school students in Namlea sub-district. This study aims to determine the effect of self-efficacy on the learning achievement of biology class $X$ students in Namlea district. This type of research is expost facto which is causality designed to explain the existence of a causal relationship between variables. The population in this study amounted to 603 students of State Senior High School in Namlea district. The sample in this study amounted to 90 students. The data analysis technique used simple linear regression analysis.The results of the analysis show that self-efficacy has a positive and significant effect on the biology learning achievement of class X SMA Negeri in Namlea sub-district. Judging from the results of simple linear regression calculations, it can be seen that the magnitude of the influence is 0.271. While the $R$ square value is 0.036. So it can be seen that the relative contribution of the effect of self-efficacy on learning achievement is $36.0 \%$, while $64 \%$ is influenced by other variables not examined in the study.
\end{abstract}

Keyword: Self-Efficacy, Learning, Achievement

\section{PENDAHULUAN}

Dalam dunia pendidikan formal, mata pelajaran biologi merupakan mata pelajaran wajib yang harus dipelajari siswa SMA sehingga menjadi salah satu mata pelajaran yang diujikan pada Ujian Akhir Nasional. Dalam kehidupan sehari-hari, biologi berkaitan 
dengan cara mencari tahu dan memahami tentang alam secara sistematis, sehingga biologi bukan hanya sekedar penguasaan kumpulan yang berupa fakta, konsep atau prinsip saja tetapi juga merupakan proses penemuan. Oleh karena itu, biologi dianggap memegang peranan penting dalam kepentingan akademis maupun dalam kehidupan seharihari.Pentingnya mata pelajaran biologi tidak sejalan dengan hasil belajar yang diperoleh siswa saat ini.

Kenyataan menunjukkan bahwa rata-rata nilai biologi secara Nasional pada UAN 2019 masih dibawah standar pencapaian lulusan (Pusat Penilaian Pendidikan, 2019). Hasil observasi pada siswa kelas X SMA Negeri se-Kecamatan Namlea juga menunjukan bahwa rata-rata hasil belajar biologi masih rendah karena rata-rata siswa belum mencapai KKM yang ditetapkan sekolah.Rendahnya prestasi biologi siswa, dipengaruhi oleh banyak faktor. Menurut Slameto (2013) faktor-faktor yang mempengaruhi prestasi belajar dapat diklasifikasikan menjadi dua, yaitu faktor internal yakni faktor yang berasal dari dalam diri individu dan faktor eksternal, yakni faktor yang berasal dari luar diri individu.

Salah satu faktor internal yang mempengaruhi pestasi belajar biologi adalah efikasi diri. Efikasi diri menurut Bandura (2010) adalah keyakinan akan kemampuan yang dimiliki untuk dapat meraih prestasi yang maksimal. Siswa yang berprestasi kurang bagus kemungkinan disebabkan oleh siswa memiliki kemampuan namun kurang memiliki efikasi diri untuk mengoptimalkan kemampuannya. Berdasarkan latar belakang maka perlu peneliti perlu melakukan penelitian dengan judul "Pengaruh Efikasi Diri Terhadap Prestasi Belajar Biologi Pada Siswa Kelas X SMA Negeri Se-Kecamatan Namlea”.

\section{METODE PENELITIAN}

Penelitian ini termasuk penelitian ex-post facto yang bersifat kausalitas yang dirancang untuk menerangkan adanya hubungan sebab akibat antar variabel. Sampel yang digunakan dalam penelitian sebanyak 90 siswa,populasi diketahui sebesar 633 siswa. Metode pengambilan sampel yang digunakan adalah proporsional random sampling.

Instrumen penelitian yang digunakan dalam penelitian ini adalah angket dan dokumentasi. Teknik analisis data yang digunakan dalam penelitian ini adalah analisis statistic deskriptif dan statistic inferensial.Statistika deskriptif dimaksudkan untuk memberi gambaran alami data variabel penelitian berupa rata-rata, standar deviasi dan analisis presentase.

Statistik inferensial dimaksudkan untuk validasi yang diusulkan dan pengujian hipotesis. Untuk keperluan pengujian hipotesis dan memeriksa validitas dan reliabilitas 
instrumen penelitian, secara keseluruhan digunakan teknik analisis bantuan paket software SPSS 24. Statistic inferensial yang dimaksudkan untuk uji prasyarat dan uji hipotesis, uji prasyarat meliputi uji normalitas, uji lenearitas.

\section{HASIL DAN PEMBAHASAN}

Berdasarkan perhitungn penssokaran klasifikasi angket efikasi diri dan prestasi belajar dapat dilihat pada tabel di bawah ini:

\section{Tabel 1. Pengklasifikasian Skor Efikasi diri Siswa}

\begin{tabular}{lcccc}
\hline No & Interval Skor & Frekuensi & Persentasi (\%) & Kategori \\
\hline 1 & $87-100$ & 0 & 0 & Sangat Rendah \\
2 & $75-86$ & 2 & 2,22 & Rendah \\
3 & $65-74$ & 31 & 34,44 & Sedang \\
4 & $50-64$ & 40 & 44.44 & Tinggi \\
5 & $30-49$ & 17 & 18,9 & Sangat Tinggi \\
\hline Jumlah & & 90 & 100 & \\
\hline
\end{tabular}

Sumber: data primer diolah 2020

Berdasarkan Tabel 1. diketahui bahwa sebanyak 17 siswa 18,9\%) memiliki efikasi diri yang sangat tinggi, 40 siswa $(44,44 \%)$ memiliki efikasi diri yang tinggi, 31 siswa $(34,44 \%)$ memiliki efikasi diri sedang, 2 siswa $(2,22 \%)$ memiliki efikasi diri rendah, dan tidak ada siswa $(0 \%)$ yang memiliki efikasi diri sangat rendah. Sehingga dapat disimpulkan bahwa efikasi diri siswa tergolong tinggi.

\section{Table 2 Analisis Deskriptif Efikasi Diri}

\begin{tabular}{l|c}
\hline \multicolumn{1}{c|}{$\mathrm{N}$} & 90 \\
\hline Mean & 84.0333 \\
Median & 84.0000 \\
Mode & 84.00 \\
Std.deviation & 6.85721 \\
Range & 34.00 \\
Minimum & 65.00 \\
Maximum & 99.00 \\
\hline
\end{tabular}

Sumber: data primer diolah 2020

Data efikasi diri diperoleh melalui angket yang dibagikan ke sejumlah responden. Data ideal memiliki rentang dari 65.00 (skor minimum) sampai skor maksimum sebesar 99.00. Berdasarkan hasil pengolahan data yang dilakukan, diperoleh nilai rata-rata (mean) sebesar 84.03, standar deviasi sebesar sebesar 6.85.

\section{Prestasi Belajar Biologi}

Gambaran tentang prestasi belajar Biologi dari 90 siswa Kelas X SMA Negeri seKecamatan Namlea dapat dilihat dari analisis deskriptif pada Tabel dibawah ini. 
Tabel 3. Pengklasifikasian Skor Tes Prestasi belajar Siswa

\begin{tabular}{lcccc}
\hline No & Interval Skor $(\%)$ & Frekuensi & Persentasi $(\%)$ & Kategori \\
\hline 1 & $90 \leq$ skor $\leq 100$ & 24 & 26.67 & Sangat Tinggi \\
2 & $75 \leq$ skor $<90$ & 36 & 40 & Tinggi \\
3 & $55 \leq$ skor $<75$ & 30 & 33,33 & Sedang \\
4 & $40 \leq$ skor $<55$ & 0 & 0 & Rendah \\
5 & $0 \leq$ skor $<40$ & 0 & 0 & Sangat Rendah \\
\hline Jumlah & & 90 & 100 & \\
\hline
\end{tabular}

Sumber : Data primer diolah 2020

Berdsarkan Tabel diatas diketahui bahwa 24 siswa (26.67\%) memiliki skor prestasi belajar yang sangat tinggi, 36 siswa (40\%) memiliki skor prestasi belajar tergolong tinggi,30 siswa (33.33\%) memiliki skor prestasi belajar siswa tergolong sedang, dan tidak ada siswa (0\%) memiliki skor prestasi belajar tergolong tinggi dan sangat tinggi. Sehingga dapat disimpulkan bahwa prestasi belajar siswa tergolong tinggi.

\section{Pengujian prasyarat analisis data}

\section{Uji normalitas data}

Uji normalitas dilakukan dengan uji kolmogrof-smirnov pada (SPSS) versi 24. Hasil analisis menunjukan uji normalitas dari variabel efikasi diri,aktivitas belajar dan kemandirian belajar terhadap prestasi belajar signifikan dari deviation from linearity 0.183> 0.05 sementara motivasi belajar memiliki nilai signifikan dari deviation from linearity

\section{Uji lineariatas}

Uji linearitas digunakan untuk mengetahui apakah antara variabel bebas dan variabel terikat mempunyai hubungan yang terikat atau tidak hasil pengujian dapat dilihat pada tabel 3 dibawah ini.

Tabel 4. uji Linearitas

\begin{tabular}{|l|l|l|l|l|l|l|}
\hline & & $\begin{array}{c}\text { sum of } \\
\text { square }\end{array}$ & df & $\begin{array}{c}\text { Mean } \\
\text { square }\end{array}$ & F & Sig \\
\hline $\begin{array}{l}\text { prestasi } \\
\text { siswa }\end{array}$ & 84.814 & 1 & 84.814 & $\begin{array}{l}2.3 \\
54\end{array}$ & .130 \\
efikasi diri & $\begin{array}{l}\text { Linear } \\
\text { itas }\end{array}$ & & & & & \\
\hline
\end{tabular}

Sumber: data primer diolah 2020

Uji linearitas dilakukan dengan menggunakan program SPSS versi 24. Hasil analisis menunjukan uji linearitas dari variabel efikasi diri terhadap prestasi belajar siswa menunjukan nilai $\mathrm{p}=0,130>0,05$ dengan demikian dapat dikatakan terdapat pengaruh efikasi diri terhadap prestasi belajar. 


\section{Pengujian Hipotesis}

1.Pengujian hipotesis pertama

Pengujian hipotesis pertama diuji dengan menggunakan analisis regresi linear sederhana yang diperoleh degan menggunakan program SPSS 24 for windows dapat dilihat pada Tabel 5.

Tabel 5. analisis regresi linear sederhana (X1 terhadap Y) coeffients

\begin{tabular}{|l|l|l|c|l|l|}
\hline \multirow{2}{*}{ Model } & \multicolumn{2}{|l|}{ Unstndardized coefficien } & Standar coefficients & $\mathrm{t}$ & \multicolumn{1}{|c|}{ Sig } \\
\cline { 2 - 3 } & $\mathrm{B}$ & Std.error & & & \\
\hline constants & 72.327 & 8.967 & & 8.066 & .000 \\
\hline $\begin{array}{l}\text { Efiasi } \\
\text { diri }\end{array}$ & .047 & .103 & 0.49 & .457 & .649 \\
\hline
\end{tabular}

Sumber :data primer diolah 2020

Regresi linear sederhana dapat diketahui besarnya nilai koefisien regresi pengaruh efikasi diri (X1) sebesar 0.047 sedangkan besar nilai konstan yaitu 72.327 Maka dapat dirumuskan dalam persamaan sebagai berikut.

$$
\begin{aligned}
& Y=a+b 1 X 1 \\
& Y=72.327+0.047
\end{aligned}
$$

Persamaan garis diatas menunjukan bahwa nilai koefisien X1 sebesar 0,047 berarti jika nilai pengaruh efikasi diri naik satu poin maka prestasi belajar pada siswa di SMA disekecamatan namlea naik sebesar 0,047. Pengujian hipotesis ini dilakukan dengan melihat nilai $\mathrm{p}$, jika nilai $\mathrm{p} 0,000<0,05$ maka dinyatakan terdapat pengaruh yang signifikan. Untuk melihat signifikansi analisis regresi dapat dilihat pada tabel 5.

Tabel 6 Anova Regresi Linear Sederhana

\begin{tabular}{|l|l|l|l|l|l|}
\hline Model & $\begin{array}{l}\text { Sum of } \\
\text { square }\end{array}$ & Df & $\begin{array}{l}\text { Mean } \\
\text { Square }\end{array}$ & F & Sig \\
\hline Regresi & 7.336 & 1 & $\begin{array}{l}7.336 \\
.20\end{array}$ & .000 \\
\hline Residual & 3096.453 & 88 & 35.187 & & \\
\hline Total & 3103.789 & 89 & & & \\
\hline
\end{tabular}

Sumber: data primer diolah 2020

Berdasarkan hasil perhitungan regresi linear berganda yang telah dikemukan bahwa dapat diketahui nilai $F_{\text {hitung }}$ sebesar .208 , nilai sig $\mathrm{p}=0.000$ lebih kecil dari alfa 0.05 $(0.130<0.05)$ dengan demikian dapat dikatakan secara statistik pengaruh efikasi diri memiliki pengaruh yang signifikan terhadap hasil belajar siswa di SMA sekecamatan 
Namlea. Besarnya kontribusi pengaruh efikasi diri, terhadap prestasi belajar Biologi di SMA sekecamatan Namlea dapat dilihat dari nilai koefisien determinasi (Rsquare) sebesar 0,052. Hal ini berarti 52,0\% hasil belajar siswa dipengaruhi oleh variabel efikasi diri, sedangkan $48 \%$ dipengaruhi oleh variabel lain yang tidak diteliti dalam penelitian. Besarnya nilai R square dapat dilihat pada tabel di bawah ini.

Tabel 7. Model Summary

\begin{tabular}{|l|l|l|l|l|}
\hline Model & \multicolumn{1}{|c|}{$\mathrm{R}$} & \multicolumn{1}{|c|}{$\mathrm{R}$ square } & Adjusted Rsquer & Std.error of the estimate \\
\hline 1 & .049 & .052 & .009 & 5.93186 \\
\hline
\end{tabular}

Sumber: data primer diolah 2020

\section{PEMBAHASAN}

Berdasarkan hasil pengujian terhadap hipotesis 1, hasil temuan menunjukkan bahwa efikasi diri berpengaruh positif dan signifikan terhadap prestasi belajar Biologi siswa Kelas X SMA Negeri se-Kecamatan Namlea, sebagaimana yang tertera pada tabel 1 menujukan nilai signifikansi $0.000<$ alpa 0,05 . Hal ini menunjukkan bahwa siswa yang memiliki efikasi diri yang tinggi dapat dengan mudah membiasakan dirinya untuk mengikuti pelajaran, memantapkan pelajaran, membaca buku, dan menghadapi ujian. Sedangkan siswa yang memiliki kecerdasan emosi rendah, memiliki kemampuan mengatur diri yang rendah dalam aktifitas belajarnya.

Efikasi diri yang baik dapat dilihat dari kemampuan mengenal emosi diri sendiri, mengendalikan diri, memotivasi diri, berempati, dan kemampuan membina hubungan sosial. Oleh karena itu, siswa yang memiliki kecerdaan emosi yang baik akan berhasil mengatur dan memotivasi dirinya untuk terus belajar sehingga aktifitas belajarnya terkontrol dengan baik. Sedangkan, siswa yang memiliki kecerdasan emosi yang kurang baik, kurang memiliki motivasi untuk belajar, sehingga dapat merusak kosentrasi belajarnya.

Hasil pengujian terhadap hipotesis 3 menunjukkan bahwa efikasi diri yang dimiliki siswa berpengaruh positif dan signifikan terhadap prestasi belajar Biologi siswa Kelas $\mathrm{X}$ SMA Negeri se-Kecamatan Namlea . sebagaimana yang tertera pada tabel 6 yang mana diketahui besarnya nilai signifikansi 0.000. dan tabel 6 menujukan pengaruh efikasi diri terhadap hasil belajar siswa sebesar 52\% Artinya, semakin baik efikasi diri yang dimiliki siswa maka akan semakin baik pula prestasi belajar Biologi siswa Kelas X SMA Negeri seKecamatan Namlea . 
Temuan penelitian ini konsisten dengan hasil penelitian Ogundokun \& Adeyemo (2010) yang menemukan bahwa terdapat pengaruh positif yang signifikan antara efikasi diri dan prestasi belajar siswa.

Siswa yang memiliki kecerdaan emosi yang baik akan berhasil mengatur dan memotivasi dirinya untuk terus belajar sehingga aktifitas belajarnya terkontrol dengan baik dan berdampak pada baiknya prestasi belajar yang diperoleh. Sebaliknya, siswa yang memiliki kecerdasan emosi yang rendah, kurang memiliki motivasi untuk belajar sehingga dapat merusak aktifitas dan kosentrasi belajarnya dan berujung pada perolehan prestasi belajar yang kurang baik.

Hal ini sesuai dengan pendapat Riyanto (2012: 253) yang mengungkapkan bahwa salah satu factor yang dapat mendukung keberhasilan belajar siswa adalah kemampuan siswa menggunakan (mengelola) emosinya secara efektif untuk mencapai tujuan,mengembangkan hubungan yang produktif dengan orang lain dan meraih keberhasilan, yang sering disebut dengan kecerdasan emosional.

\section{SIMPULAN}

Berdasarkan hasil analisis data yang di dapatkan dapat di simpulkan terdapat hubungan yang yang signifikan antara pengaruh efikasi diri dan hasil belajar siswa kls X di SMA sekecamatan Namlea. Hal ini dapat dilihat dari taraf signifikan 0,000 lebih kecil dari alfa 0,05 .

\section{SARAN}

Berdasarkan hasil penelitian dan kesimpulan, maka saran yang dapat diberikan dari hasil penelitian adalah sebagai:

a. Bagi Peneliti mengungkapkan prestasi belajar dengan melibatkan variabel efikasi diri diinformasi bahwa efikasi diri memberikan sumbangan terhadap prestasi belajar siswa sebesar $52 \%$ dan sisanya $48 \%$ dipengaruhi oleh faktor lain yang tidak diteliti dalam penelitian ini, seperti faktor minat, faktor fsikologis, faktor keluarga dan faktor yang lain.

b. Bagi pihak sekolah Untuk terus meningkatkan kualitas pribadi melalui pengembangan diri sendiri dengan membaca dan mengkaji literatur tentang proses pembelajaran yang baik. guru diharapkan lebih banyak memperhatikan dan memberikan motivasi baik yang kepada siswanya tanpa membedakan status sosial dari siswa tersebut. 


\section{DAFTAR PUSTAKA}

Aini, Prastya. Nor., dan Taman, Abdullah. (2012). Pengaruh Kemandirian Belajar Dan Lingkungan Belajar Siswa Terhadap Prestasi Belajar Akuntansi Siswa Kelas XI IPS SMA Negeri 1 Sewon Bantul Tahun Ajaran 2010/2011. Jurnal Pendidikan Akuntansi Indonesia, 10(1). https://doi.org/10.21831/jpai.v10i1.921

Desmita. 2011. Psikologi Perkembangan Peserta Didik. Bandung: Remaja Rosdakarya.

Effendi, Mursilah, dan Mujiono. (2018). Korelasi Tingkat Perhatian Orang Tua dan Kemandirian Belajar dengan Prestasi Belajar Siswa. Titian Ilmu: Jurnal Ilmiah Multi Sciences, 10(1), 17-23. https://doi.org/10.30599/jti.v10i1.131

Monika dan Adman. (2017). Peran Efikasi Diri Dan Motivasi Belajar Dalam Meningkatkan Hasil Belajar Siswa Sekolah Menengah Kejuruan. Jurnal Pendidikan Manajemen Perkantoran, 2(2), 109. https://doi.org/10.17509/ipm.v2i2.8111

Pusat Penilaian Pendidikan Kementerian Pendidikan dan Kebuadayaan, 2019. Laporan HasilUjianNasional.https://hasilun.puspendik.kemdikbud.go.id/\#2019!smp!capaian nasio nal!99\&99\&999!T\&T\&T\&T\&1\&11!\&

Rahayu, Reka dan Susanto, Ratnawati. (2018). Pengaruh Kepemimpinan Guru Dan Keterampilan Manajemen Kelas Terhadap Perilaku Belajar Siswa Kelas Iv. Jurnal Pendidikan Dasar Perkhasa: Jurnal Penelitian Pendidikan Dasar, 4(2), 220-229. https://doi.org/10.31932/jpdp.v4i2.178

Rahmania, Yunita., \& Ismiyati. (2019). Pengaruh Efikasi Diri, Komunikasi Interpersonal Guru Dan Media Pembelajaran Terhadap Perilaku Belajar. Economic Education Analysis Journal, 7(3), 1115-1129. https://doi.org/10.15294/eeaj.v7i3.28344

Soemanto, Wasty. 2012. Psikologi Pendidikan. Jakarta: Rineka Cipta.

Syafi'i, Ahamad., Marfiyanto, Ttri dan Rodiyah, Siti. Kholidatur. (2018). Studi Tentang Prestasi Belajar Siswa Dalam Berbagai Aspek Dan Faktor Yang Mempengaruhi. Jurnal Komunikasi Pendidikan, 2(2), 115. https://doi.org/10.32585/ikp.v2i2.114

Wahyuningsih, Sri., dan Djazari, M. (2013). Pengaruh Lingkungan Sekolah dan Kebiasaan Belajar Terhadap Prestasi Belajar Akuntansi Siswa Kelas XI IPS SMA Megeri 1 Srandakan. Kajian Pendidikan \& Akuntansi Indonesia, 2(1), 137-160. https://doi.org/http://download.portalgaruda.org/article.php 